\title{
Relationship between kidney volume and body indexes in the Turkish population determined using ultrasonography
}

Aylin Okur ${ }^{1}$, Halil Ibrahim Serin ${ }^{1}$, Kursad Zengin², Mustafa Fatih Erkoc³ ${ }^{3}$ Serhat Tanık², Ugur Yıldırım, Seyhan Karaçavus ${ }^{4}$, Lutfi Akyol ${ }^{5}$

${ }^{1}$ Department of Radiology, Bozok University Medical Faculty, Yozgat, Turkey; ${ }^{2}$ Department of Urology, Bozok University Medical Faculty, Yozgat, Turkey; ${ }^{3}$ Department of Radiology, Sivas Numune Hospital, Sivas, Turkey; ${ }^{4}$ Department of Nuclear Medicine, Bozok University Medical Faculty, Yozgat, Turkey; ${ }^{5}$ Department of Internal Medicine, Bozok University Medical Faculty, Yozgat, Turkey

\section{ABSTRACT}

Objective: To estimate the kidney volume of the healthy Turkish population using ultrasound and to evaluate the relationship between kidney volume and body indexes. Materials and methods: Kidney ultrasound evaluation was performed on 152 patients (mean age: $42 \pm 13.7$ years). Kidney length, width and thickness were measured using ultrasound. Mean total and parenchymal volume were also calculated. Patients' age, sex, weight, height and body mass index (BMI) $\left(\mathrm{kg} / \mathrm{m}^{2}\right)$ were recorded.

Results: According to ultrasound, kidney lengths were $10.3 \pm 7.8 \mathrm{~cm}$ for the right and $10.4 \pm 9 \mathrm{~cm}$ for the left. Volumes were $158 \pm 39 \mathrm{~cm}^{3}$ for the right and $168 \pm 40 \mathrm{~cm}^{3}$ for the left. Volumes in women were $151.8 \pm 39 \mathrm{~cm}^{3}$ for the right and $159.8 \pm 37 \mathrm{~cm}^{3}$ for the left, and $164.3 \pm 38 \mathrm{~cm}^{3}$ for the right and $175.8 \pm 41 \mathrm{~cm}^{3}$ for the left in men. Kidney measurements correlated with body height and weight. A strong correlation with total kidney volume and kidney measurements was determined for body weight for both kidneys $(\mathrm{p}<0.001)$. A significant correlation with kidney volume and width was determined for both kidneys $(\mathrm{p}<0.001)$. A positive correlation was also found between parenchymal and total kidney volume for both kidneys $(p<0.001)$.

Conclusion: The most significant factors associated with kidney volume for both kidneys in the Turkish population are kidney width and body weight. Measuring kidney volume with ultrasound is a feasible modality and is widely available for daily clinical practice.

\section{ARTICLE INFO}

Key words:

Kidney; Ultrasonography; Body

Mass Index

Int Braz J Urol. 2014; 40: 816-22

Submitted for publication:

September 16, 2013

Accepted after revision:

March 19, 2014

\section{INTRODUCTION}

Ultrasonography (US) of the kidneys has replaced imaging modalities for the evaluation of kidney diseases and provides many advantages over other imaging methods (use of non-ionizing radiation, non-invasive method, little or no patient preparation, no use of medication or injection of contrast agent). It is also readily available, economical and easily reproducible to a large extent $(1,2)$.
Kidney length and volume are important parameters in clinical settings, such as in acute and chronic renal disease and recurrent urinary tract infection (2). Previous studies have shown a direct evidence of the balance between donor graft volume and recipient metabolic demand on early graft function of transplantation patients (3). Moreover, it was reported that if the donor graft mass is inferior to recipient's BMI, the incidence of acute allograft rejection is higher (4). 
In this study, we measured the kidney volumes of healthy individuals using US and evaluated the relationship between kidney volume and body indexes.

\section{MATERIALS AND METHODS}

\section{Patients and Clinical Assessment}

One hundred and fifty-two subjects (79 women, $73 \mathrm{men}$ ) referred to our clinic for genitourinary and abdominal US imaging were included in the study. The study population consisted of outpatients and inpatients undergoing US examination due to common clinical complaints such as weight loss, unexplained abdominal pain, nausea and constipation. We also reviewed patients' medical records and laboratory findings.

Patients' age, sex, weight, height and body mass index (BMI) $\left(\mathrm{kg} / \mathrm{m}^{2}\right)$ were recorded. Subjects with underlying disease such as hypertension, diabetes mellitus and heart disease or any abnormal finding at US examination, such as renal cysts, hydronephrosis, single kidney, kidney stone and mass, increased parenchymal echogenicity, extreme obesity or pregnancy, or abnormal laboratory findings were excluded. The institutional ethics committee approved the study.

\section{Sonographic evaluation}

A systematic abdominal sonographic examination (4.5-5 MHz convex array transducer, Aloka alfa 6, Japan) was performed on all patients. The examination was performed with the subject in a supine and prone positions. Kidney measurements were obtained with the subject prone. Kidney length, wi$\mathrm{dth}$ and thickness were measured using US. Kidney volume (total volume (Figure-1) and sinus volume (Figure-2)): lenght $\mathrm{x}$ thickness $\mathrm{x}$ width $\mathrm{x} 0.523$ (5) were obtained. Parenchymal volume was calculated as total volume- sinus volume. RI was calculated automatically by Doppler US (Figure-3).

\section{Statistical analysis}

Statistical analysis was performed using the Statistical Package for the Social Sciences (SPSS) 18.0 software package (Version 18, SPSS Inc., Chicago, IL, USA). Parameters were expressed as mean ${ }_{ \pm} \mathrm{SD}$. Student's t-test was used to compare continuous variables. Pearson correlation coefficients were used to evaluate the strength of association between ultrasonographic parameters with each other and with other parameters, and were expressed as $r^{2}$. Statistical significance was set at $\mathrm{p}<0.05$.

\section{RESULTS}

Three hundred and four kidneys of 152 patients ranging in age from 25 to 65 years (mean: $42 \pm 13.7$ years) and undergoing US were examined. Seventy-nine patients were female and 73 male. Patients' mean age, BMI, height, weight and RI are shown in Table-1. Mean kidney lengths and total and parenchymal volumes are shown in Table-2. Mean

Figure 1 - Measurement of total kidney volume on the US image. T indicates thickness, W, width; L, length.

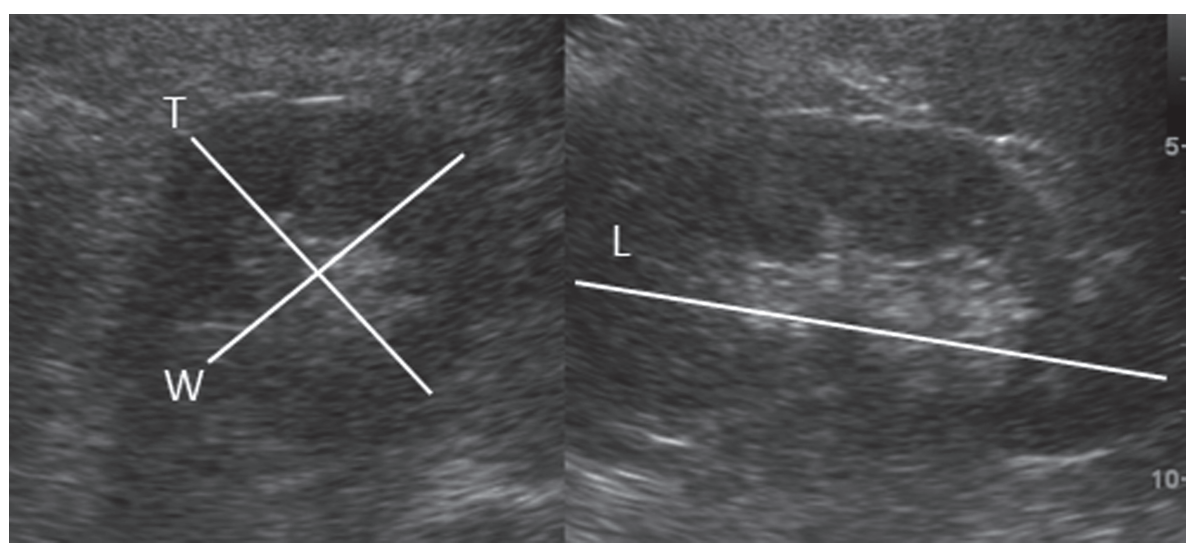


Figure 2 - Measurement of kidney sinus volume on the US image. T indicates thickness, W, width; L, length.

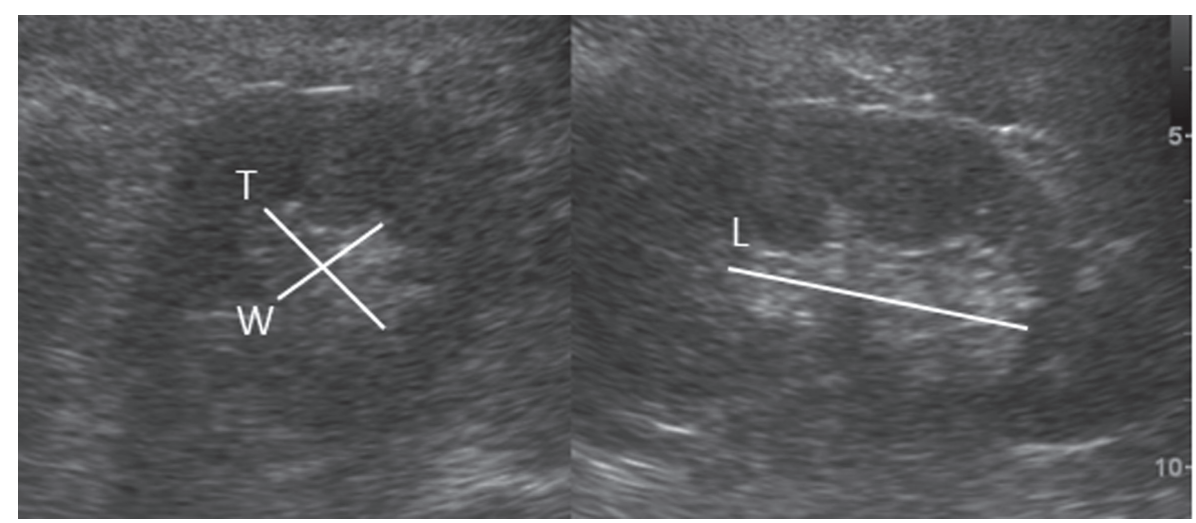

Figure 3 - Doppler waveform and measurement of RI for the intrarenal artery.

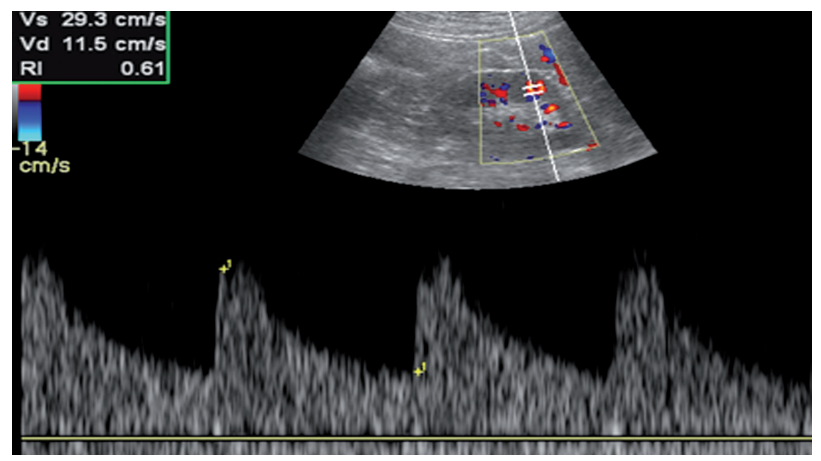

kidney volume was significantly larger among males $(\mathrm{p}<0.05)$. The correlations between patients' kidney dimensions and body parameters are shown in Table-3.

Kidney measurements were correlated with body height and weight. A positive correlation was observed between body height and kidney length and width $(\mathrm{p}=0.005)$. A significant positive correlation was also observed between body weight and kidney length and width $(\mathrm{p}<0.001)$. There was no correlation between anteroposterior kidney measurements and body height or weight. A significant correlation with total kidney volume and kidney measurements was determined for body weight in both kidneys ( $\mathrm{p}<0.001, \mathrm{r}$ : 0.32-0.44). A strong correlation was found between kidney volume and body weight compared to body height $(\mathrm{p}<0.001, \mathrm{p}<0.05$, respectively, Figure-4). A significant correlation with kidney volume and width was revealed for both kidneys $(p<0.001$, Figure-5). A positive correlation was observed between parenchymal and total kidney volumes for both kidneys $(\mathrm{p}<0.001)$. Left kidney volume was significantly greater than right $(\mathrm{p}<0.05)$.

There was no correlation between kidney dimensions and volumes and RI. A negative but insignificant correlation was determined between

Table 1 - Demographic characteristics.

\begin{tabular}{lccc}
\hline Characteristics & Women & Men & \\
\hline Patients & 79 & 73 & $>0.05$ \\
Age $(\mathrm{yrs})$ & $41 \pm 13$ & $44 \pm 14$ & $<0.001$ \\
Height $(\mathrm{cm})$ & $160 \pm 7$ & $168 \pm 12$ & $<0.005$ \\
Weight $(\mathrm{kg})$ & $71 \pm 12$ & $77 \pm 11$ & $>0.05$ \\
BMl $\left(\mathrm{kg} / \mathrm{m}^{2}\right)$ & $27 \pm 6$ & $28 \pm 5$ & $>0.05$ \\
$\mathrm{Rl}$ & $0.62 \pm 0.08$ & $0.60 \pm 0.06$ & \\
\hline
\end{tabular}

$\mathbf{R} \mathbf{I}=$ Resistivity index, $\mathbf{B M I}=$ Body mass index 
Table 2 - Mean kidney length, volume and RI.

\begin{tabular}{lcccccc}
\hline & \multicolumn{2}{c}{ Women } & \multicolumn{2}{c}{ Men } & \multicolumn{2}{c}{ Total } \\
\hline Mean \pm SD & Right kidney & Left kidney & Right kidney & Left kidney & Right kidney & Left kidney \\
Length $(\mathbf{c m})$ & $102 \pm 7.6$ & $101 \pm 11.1$ & $105 \pm 7.6$ & $107.7 \pm 6.9$ & $10.3 \pm 7.8$ & $10.4 \pm 9$ \\
Total volume $\left(\mathbf{c m}^{3}\right)$ & $151.8 \pm 39$ & $159.8 \pm 37$ & $164.3 \pm 38$ & $175.8 \pm 41$ & $158 \pm 39$ & $168 \pm 40$ \\
Parenchymal volume $\left(\mathbf{c m}^{3}\right)$ & $123.8 \pm 32.2$ & $128.5 \pm 31.2$ & $129.5 \pm 36.8$ & $137.5 \pm 38.4$ & $126 \pm 34$ & $133 \pm 35$ \\
RI & $0.62 \pm 0.08$ & $0.60 \pm 0.08$ & $0.63 \pm 0.08$ & $0.64 \pm 0.07$ & $0.63 \pm 0.08$ & $0.62 \pm 0.08$ \\
\hline
\end{tabular}

$\mathbf{R} \mathbf{I}=$ Resistivity index

Table 3 - Correlation between patients' kidney dimensions and body parameters.

\begin{tabular}{lcccccccccc}
\hline \multirow{2}{*}{$\begin{array}{l}\text { Body } \\
\text { parameter }\end{array}$} & \multicolumn{2}{c}{$\mathrm{MKL}$} & \multicolumn{2}{c}{ MKT } & \multicolumn{2}{c}{ MKW } & \multicolumn{2}{c}{ MKTV } & \multicolumn{2}{c}{ MKPV } \\
\cline { 2 - 11 } & $\mathrm{R}$ & $\mathrm{L}$ & $\mathrm{R}$ & $\mathrm{L}$ & $\mathrm{R}$ & $\mathrm{L}$ & $\mathrm{R}$ & $\mathrm{L}$ & $\mathrm{R}$ & $\mathrm{L}$ \\
\hline Height & $0.23^{* *}$ & $0.23^{* *}$ & 0.07 & 0.02 & $0.23^{* *}$ & $0.20^{*}$ & $0.22^{* *}$ & 0.15 & $0.20^{*}$ & 0.10 \\
Weight & $0.32^{* *}$ & $0.38^{* *}$ & $0.28^{* *}$ & 0.14 & $0.23^{* *}$ & $0.22^{* *}$ & $0.39^{* *}$ & $0.35^{* *}$ & $0.35^{* *}$ & $0.30^{* *}$ \\
BMI & 0.07 & 0.15 & 0.09 & 0.09 & 0.07 & 0.04 & 0.12 & $0.17^{*}$ & 0.10 & $0.18^{*}$ \\
Age & -0.07 & 0.05 & -0.02 & 0.07 & -0.02 & -0.02 & -0.03 & 0.02 & -0.08 & -0.03 \\
\hline
\end{tabular}

${ }^{*} \mathbf{p}<\mathbf{0 . 0 5} ;{ }^{*} \mathbf{p}<\mathbf{0 . 0 0 1} ; \mathbf{M K L}=$ mean kidney length; MKT = mean kidney thickness; $\mathbf{M K W}=$ mean kidney width; $\mathbf{M K T V}=$ mean kidney total volume; $\mathbf{M K P V}=$ mean kidney parenchymal volume; $\mathbf{R}=$ Right; $\mathbf{L}=$ Left; $\mathbf{B M I}=$ body mass index

kidney dimensions and volumes and age. A weak correlation with left kidney volume was observed for BMI $(\mathrm{p}<0.05, \mathrm{r}$ : 0.20). A mild correlation with parenchymal volume and total volume was observed for BMI for both right and left kidneys ( $\mathrm{p}<0.05)$. However, left kidney volume correlated better with BMI, in contrast to previous studies $(4,4-12)$. There was no significant correlation between total and parenchymal kidney volumes and RI for either kidney $(p>0.05)$. Gender showed the weakest correlation with kidney dimensions ( $\mathrm{p}<0.05, \mathrm{r}: 0.20-0.23)$.

\section{DISCUSSION}

Kidney length and volume measurements are generally preferred as the basis for decisions concerning renal disease and are regarded as surrogates for renal function. Measurement of kidney volume with US is a simple and noninvasive me- thod (2). Kidney volume is more of an approximation of size than length because the shape of the kidney varies considerably. It is also an excellent indicator of renal function and correlates very well with body indexes (6).

A limited number of studies have measured normal kidney volume using various imaging methods $(7,8)$. Shin et al. measured volume in the Korean population using multidetector computed tomography (MDCT) (9). The advantage of using MDCT is that the shape of the kidney is irrelevant. However, it is ionizing, potentially nephrotoxic because of the use of contrast media and is not particularly practical. Cheong et al. measured kidney volume and kidney length using magnetic resonance imaging (MRI) (8). However, MRI is expensive and time consuming and is not widely available for daily clinical practice in most countries.

US is the most widely used imaging method for kidney measurements (10). It is cheap, 
Figure 4 - Relation between mean kidney volume $\left(\mathrm{cm}^{3}\right)$ and body weight $(\mathrm{cm})$.

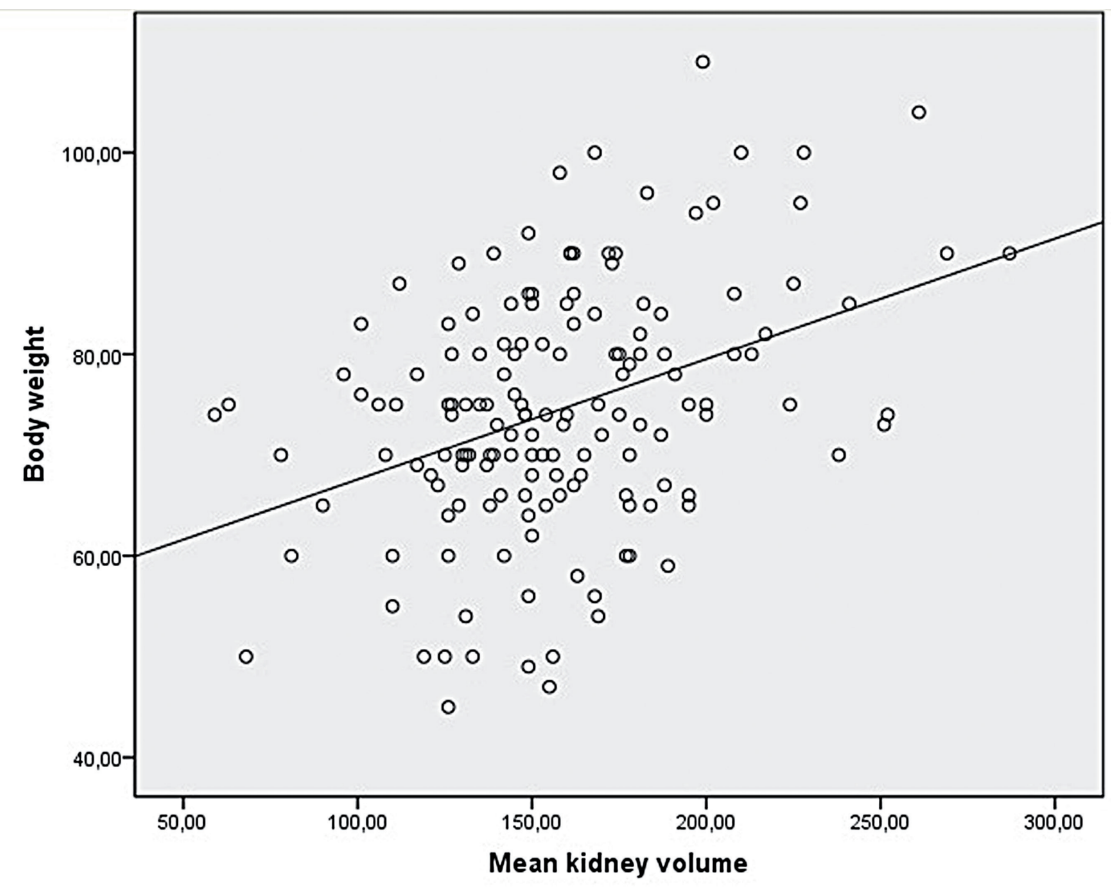

Figure 5 - Relation between mean kidney volume $\left(\mathrm{cm}^{3}\right)$ and kidney width $(\mathrm{cm})$.

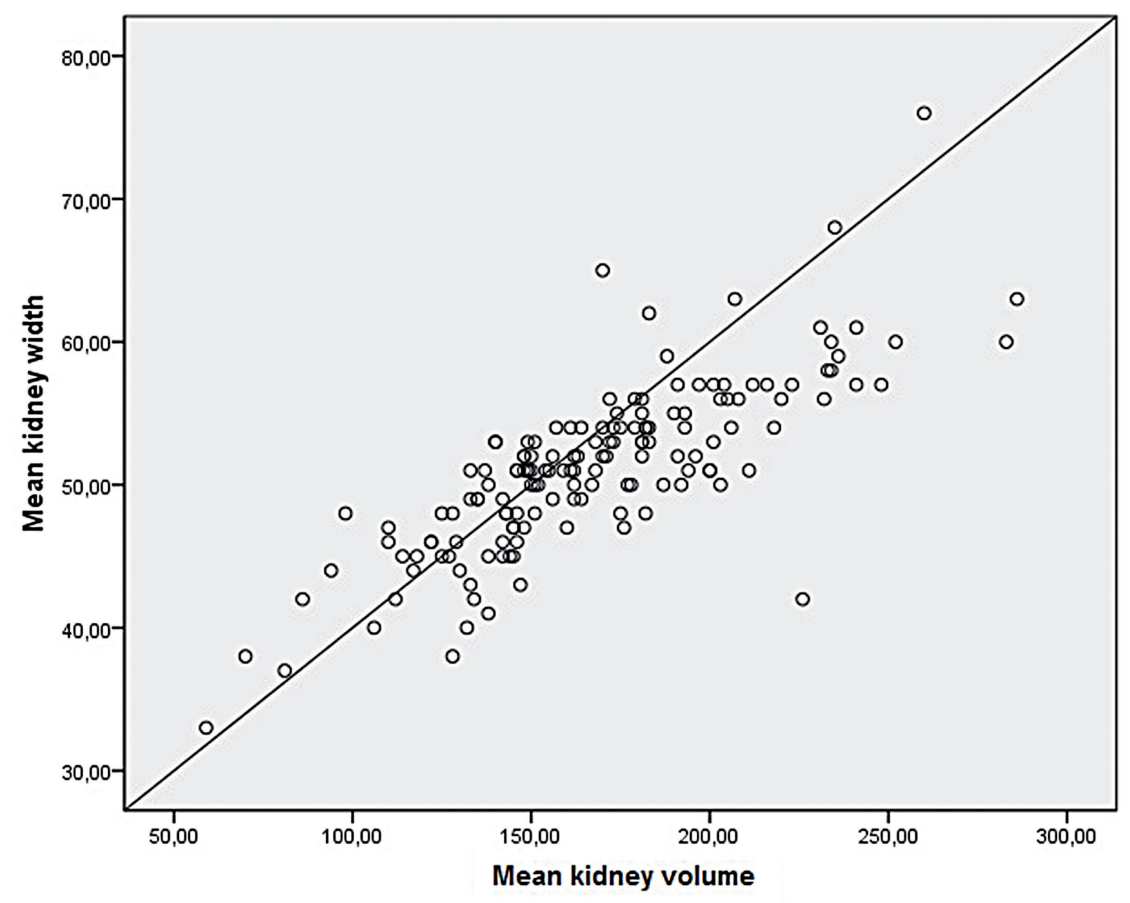


fast, and easily available. US is useful in renal disease assessment because of its low cost and the short examination time involved. Sonographically, the kidney consists of a central highly echogenic core called the kidney sinus, surrounded by a comparatively less echogenic area called the kidney parenchyma. Total kidney volume comprises both the kidney sinus and the kidney parenchyma. Measurement of kidney dimensions using US was investigated by Dixit et al. (11). In this study we used US to measure kidney volume in a Turkish population.

Mean kidney volume and length of $205.29 \pm 36.81 \mathrm{~cm}^{3}$ and $10.8 \pm 0.69 \mathrm{~cm}$, respectively, were reported in a study by Shin et al. They also found that the mean length of the left kidney was greater than that of the right (9). One study reported mean kidney lengths of $11.2 \mathrm{~cm}$ on the left and $10.9 \mathrm{~cm}$ on the right. It reported mean kidney volumes of $146 \mathrm{~cm}^{3}$ in the left kidney and $134 \mathrm{~cm}^{3}$ in the right (12). In this study, mean kidney lengths were $10.3 \pm 10 \mathrm{~cm}$ for both. Mean volumes of the right and left kidneys were $160.5 \pm 39$ $\mathrm{cm}^{3}$ and $168.2 \pm 40 \mathrm{~cm}^{3}$, respectively. Left kidney volume was also significantly greater than right kidney volume. This may be because the spleen is smaller than the liver, so the left kidney has more space for growth. Another possible explanation is that the left renal artery is shorter than the right. Increased blood flow in the left renal artery may therefore cause a relative increase in left kidney volume. Our mean kidney volumes differed slightly from those of other studies. This may possibly be due to differences among ethnic groups.

Studies have reported that both kidney volume and length were significantly correlated with all body indexes (9). Body weight showed the best correlation with right kidney dimensions, whereas BMI and age showed the weakest correlations with body indexes (13). Gavela et al. reported a good correlation between kidney parameters and body parameters, with height exhibiting the best correlation (14). Cheong et al. found no correlation between kidney volume and BMI, height or weight (8). Previous studies have shown that the kidney becomes relatively shorter and thicker with age (15). Kidney size decreasing with age is almost entirely due to parenchymal reduction (12). Some studies have reported that kidneys are larger in males than in females $(12,16)$.

Our study revealed a significant correlation with kidney volume and width for both kidneys $(p<0.001)$. A correlation with total kidney volume and measurements was determined for body weight for both kidneys. Left kidney volume correlated better with BMI than in previous studies $(12,17)$. A strong correlation was determined between kidney volume and body weight in previous reports, although our study revealed only a very weak correlation between kidney volume and body height. In contrast to previous reports, our results reveal no significant difference between kidney volumes and measurements at any age (9). Mean kidney volume was significantly greater in males. This may be due to the greater body height and weight observed in males.

RI is a parameter which correlates with renal function, and it is logical that RI should increase when renal function decreases. Kidney volume and RI are predictors of renal function and correlate with body indexes (6). Mean RIs for left and right kidneys were 0.60 and 0.62 , respectively, in our study. There was no significant correlation between total and parenchymal kidney volume and RI for either kidney $(p<0.05)$.

Our study has certain limitations. The main limitation of this study is that US is an operator-dependent technique. In present study, only healthy population was used. Lack of patients of the transplant kidney group or with renal disease also limited the study.

In conclusion, of all the variables assessed in our study, the most significant factors associated with kidney volume are kidney width and body weight for the Turkish population. Because kidney volume is important for renal functional reserve after partial nephrectomy, serial measurements can provide information regarding disease progression or stability. US examination is a feasible method for measurement of kidney volume and it is available on daily clinical practice.

\section{CONFLICT OF INTEREST}

None declared. 


\section{REFERENCES}

1. Han BK, Babcock DS: Sonographic measurements and appearance of normal kidneys in children. AJR Am J Roentgenol. 1985; 145: 611-6.

2. Bakker J, Olree $M$, Kaatee $R$, de Lange EE, Moons KG, Beutler JJ, et al.: Renal volume measurements: accuracy and repeatability of US compared with that of MR imaging. Radiology. 1999; 211: 623-8.

3. Oh CK, Jeon KO, Kim HJ, Kim SI, Kim YS, Pelletier SJ: Metabolic demand and renal mass supply affecting the early graft function after living donor kidney transplantation. Kidney Int. 2005; 67: 744-9.

4. Pourmand G, Taheri M, Mehrsai AR, Nourijelyani K: Impact of donor nephron mass on outcomes in renal transplantation. Transplant Proc. 2001; 33: 2828-9.

5. Hricak H, Lieto RP: Sonographic determination of renal volume. Radiology. 1983; 148: 311-2.

6. Widjaja E, Oxtoby JW, Hale TL, Jones PW, Harden PN, McCall IW: Ultrasound measured renal length versus low dose CT volume in predicting single kidney glomerular filtration rate. Br J Radiol. 2004; 77: 759-64.

7. Geraghty EM, Boone JM, McGahan JP, Jain K: Normal organ volume assessment from abdominal CT. Abdom Imaging. 2004; 29: 482-90.

8. Cheong B, Muthupillai R, Rubin MF, Flamm SD: Normal values for renal length and volume as measured by magnetic resonance imaging. Clin J Am Soc Nephrol. 2007; 2: 38-45.

9. Shin HS, Chung BH, Lee SE, Kim WJ, Ha HI, Yang CW: Measurement of kidney volume with multi-detector computed tomography scanning in young Korean. Yonsei Med J. 2009; 50: 262-5.

10. Jones TB, Riddick LR, Harpen MD, Dubuisson RL, Samuels $\mathrm{D}$ : Ultrasonographic determination of renal mass and renal volume. J Ultrasound Med. 1983; 2: 151-4.
11. Dixit PK, Sahai SB, Rath B, Garg A, Chowdhury V: Norms for renal parenchymal volume in Indian children. Indian Pediatr. 1994; 31: 1059-64.

12. Emamian SA, Nielsen MB, Pedersen JF, Ytte L: Kidney dimensions at sonography: correlation with age, sex, and habitus in 665 adult volunteers. AJR Am J Roentgenol. 1993; 160: 83-6.

13. Safak AA, Simsek E, Bahcebasi T: Sonographic assessment of the normal limits and percentile curves of liver, spleen, and kidney dimensions in healthy school-aged children. $J$ Ultrasound Med. 2005; 24: 1359-64.

14. Gavela T, Sánchez Bayle M, Gómez Mardones G, Gallego S, Martínez-Pérez J, Moya MT: [Ecographic study of kidney size in children]. Nefrologia. 2006; 26: 325-9.

15. Al-Khader AA, Tamim H, Sulaiman MH, Jondeby MS, Taher $\mathrm{S}$, Hejaili FF, et al:: What is the most appropriate formula to use in estimating glomerular filtration rate in adult Arabs without kidney disease? Ren Fail. 2008; 30: 205-8.

16. Raman GV, Clark A, Campbell S, Watkins L, Osmond C: Is blood pressure related to kidney size and shape? Nephrol Dial Transplant. 1998; 13: 728-30.

17. Egberongbe AA, Adetiloye VA, Adeyinka AO, Afolabi OT, Akintomide A0, Ayoola 00: Evaluation of renal volume by ultrasonography in patients with essential hypertension in Ile-Ife, south western Nigeria. Libyan J Med. 2010; 5.

Correspondence address: Aylin Okur, MD

Adnan Menderes Bulvarım, 42 Yozgat, Turkey Phone: + 90533 491-0575

E-mail: draylinokur@hotmail.com 